\title{
Phenomenology Applied to Animal Health and Suffering
}

\author{
Walter Veit ${ }^{1}$ and Heather Browning ${ }^{2}$ \\ ${ }^{1}$ The University of Sydney \\ ${ }^{2}$ Australian National University
}

\begin{abstract}
What is it like to be a bat? What is it like to be sick? These two questions are much closer to one another than has hitherto been acknowledged. Indeed, both raise a number of related, albeit very complex, philosophical problems. In recent years, the phenomenology of health and disease has become a major topic in bioethics and the philosophy of medicine, owing much to the work of Havi Carel (2007, 2011, 2018). Surprisingly little attention, however, has been given to the phenomenology of animal health and suffering. This omission shall be remedied here, laying the groundwork for the phenomenological evaluation of animal health and suffering.
\end{abstract}

Keywords: phenomenology; animals; health; illness; consciousness; sentience 


\section{Introduction}

What is it like to be a bat? ${ }^{1}$ What is it like to be sick? These two questions are much closer to one another than has hitherto been acknowledged. Indeed, both raise a number of related, albeit very complex, philosophical problems. Within the literature, there is a common tendency to draw a distinction between 'disease' and 'illness'. While disease is often taken to be an objective judgement (i.e. one of pathology), illness is taken to involve the subjective experience of pathological states: i.e. an awareness that something is 'wrong' with one's body, often through the experience of pain. In recent years, the phenomenology of health and disease has become a major topic in bioethics and the philosophy of medicine, owing much to the work of Havi Carel $(2007,2011,2018)$. Surprisingly little attention, however, has been given to the phenomenology of animal health and suffering, an omission that shall be remedied here. Drawing on empirical work such as Qualitative Behavioural Assessment (QBA), phantom limb pain and selfmedication by animals, we argue that a phenomenological approach to animal health can provide a far richer understanding of what it means for an animal to be in a pathological state.

This chapter is organized as follows: in Section Two we begin by briefly outlining the phenomenological tradition. In Section Three we survey the phenomenological tradition from Merleau-Ponty to Havi Carel and the application of embodied phenomenology to the phenomenology of illness, thus building the groundwork to apply the tools of phenomenology to animals. Section Four shows how, despite the inability of animals to verbalize their subjective experience, we can use embodied measures to understand their phenomenology. Section Five illustrates how the phenomenology of animal health and suffering should impact our treatment of other animals, before we finally conclude the chapter in Section Six with a call for perspectival pluralism regarding animal experience, particularly health and suffering, with the inclusion of a phenomenological perspective.

\section{The Phenomenological Tradition}

Phenomenology, born in the early twentieth century, is a rather young philosophical tradition that studies the nature of experience and consciousness. It is thus somewhat opposed to an older philosophical tradition going back as far as Ancient Greece, that was concerned with the nature of reality - i.e. how things

1 Thomas Nagel employed this phrase in his famous paper: "What Is It Like to Be a Bat?" (1974) The Philosophical Review 83(4): 435-50. 
really are, rather than how they appear to us. Phenomena are thus the centre of attention: how do things appear to us or, more generally, to any conscious beings? Havi Carel (2011) goes so far as to call it "the science (logos) of relating consciousness to phenomena (things as they appear to us) rather than to pragmata (things as they are)" (34).

While we think this is stretching the definition of science - after all, Carel notes that phenomenology is more of a practice than a system - there is an important sense in which phenomenology can be understood as a science: that is via its links to the emerging science of sentience and consciousness. This link will later become important when we draw on phenomenological work to enrich research on animal welfare and health. ${ }^{2}$ Proponents of the phenomenological tradition in philosophy praise its metaphysical modesty:

"[Phenomenology] focuses on the data available to human consciousness while bracketing metaphysical debates and ontological commitments. Classical phenomenology does not posit this data as empirical, real, or absolute, but rather, as transcendental. [...] It simply describes the mental activity taking place in different acts of consciousness, such as perceiving, thinking, knowing, imagining, and so on. Because of its metaphysical modesty, phenomenology can be applied to a range of philosophical problems and be used compatibly with a range of metaphysical views."

- Havi Carel $(2011,34)$

Indeed, phenomenological approaches have been used in diverse fields such as "sociology, film studies, anthropology, nursing, musicology, and others" (Carel 2011, 34). But as both this list and the quote above make abundantly clear, phenomenology traditionally conceived is about human experience. Carel (2011) doubles down on this point, stating that phenomenology is a method "for discerning and describing human experience" (34). Phenomenology can thus be understood as a practice, a method, and a science. But perhaps it is more accurate to see the term as an umbrella term for a set of positions, works, and thinkers with a rather loose family resemblance.

There is no reason to think that phenomenology must be about humans, despite assertions that can be interpreted to the contrary: "[m]an can never be an animal; his life is always more or less integrated than that of an animal" (Merleau-

${ }^{2}$ We follow the biomedical and bioethical tradition and take these concepts to be distinct (see Veit 2018b,c,d). 
Ponty 1983, 181). ${ }^{3}$ While both Edmund Husserl and Merleau-Ponty wrote much of value about the lives of animals, they held that their points of view will be in an important sense closed off from human understanding. Some of their followers were more optimistic, with some in this tradition even trying to apply phenomenology to plants (Marder 2012). Such views have, unfortunately, remained at the fringe of both the phenomenological tradition and mainstream in philosophy. Work in phenomenology at large, has turned most of its attention away from animals - partially due to assumption that we cannot know what their life would be like. We consider this a self-imposed barrier, rather than a limit inherent to the method. In order to apply phenomenology to animals, however, we need to loosen these self-imposed shackles, as we begin to do in this chapter. Here, we take Havi Carel's $(2007 ; 2011 ; 2018)$ work on the phenomenology of illness to provide a useful starting point towards discussion of phenomenology of animal health and suffering.

\section{What is it like to be?}

Prior to Havi Carel, only a small number of authors worked on the phenomenology of illness, yet it is important to also recognize their contributions. One noticeable pioneer of this approach was Richard Zaner (1981, 2005), who sought proximity to medical practice. Indeed, he worked as a clinical ethicist in a university hospital, which directly influenced his 'clinical ethics'. As Carel (2011) notes, the journal Theoretical Medicine and Bioethics dedicated an entire special issue to his work, highlighting the importance he attributed to the 'clinical encounter' with patients and families of patients (see Wiggins and Schwartz 2005; Wiggins and Sadler 2005). This focus is of less relevance when we are concerned with wild animals suffering from disease and injury, rather than human patients. Yet, there could be an interesting lens for animals in captivity that come into contact with veterinarians - a point we will briefly address in Section Four. Further important contributors in this area are Svenaeus (2000a,b, 2001) and Toombs (1988, 1987, 2001), the latter of whom has taken an explicitly transcendental approach and is thus perhaps farthest from the ideas we present here.

While there is much variety among these accounts, there is a unifying core to this foregoing work that Carel (2011) argues is best characterized as a recognition that we "need a phenomenological approach that can account for the

\footnotetext{
${ }^{3}$ We can make little sense out of the claim that the life of a human is always more or less integrated than that of an animal. The life of a bat would also always be more or less integrated than that of a salamander.
} 
body's central role in human life and acknowledge the primacy of perception" (35). This leads Carel to build her account on the work of Maurice Merleau-Ponty (1908-1961) who developed an explicitly embodied phenomenology.

\subsection{Embodied Phenomenology}

An important key in Carel's work is a sort of neutrality regarding the requirement that phenomenology must be about transcendental rather than empirical experience, arguing that: "[f]or the purposes of describing the experience of illness, it is enough to consider the general features of illness without insisting on the transcendental nature of its features" (35). Her views can thus possibly be described as a recognition that phenomenology can be a highly useful tool, even if one makes no (or only sparse) use of its transcendental history. After all, she recognizes that other phenomenologists have denied or downplayed the importance of its transcendental foundation. This is perhaps best illustrated through the anti-cognitivist movement within cognitive science, that can trace its origin back to Merleau-Ponty. Before we do so, however, let us take a closer look at Carel's usage of Merleau-Ponty's account of embodied phenomenology.

Merleau-Ponty (1962) describes human experience as having a sort of looping effect, grounding it in perceptual experience, which in turn is grounded as an embodied activity. Carel (2011) argues that this is "not just an empirical claim about perceptual activity but a transcendental view that posits the body as the condition of possibility for perception and action" (35). The body is thus the origin of the "expressive movement itself, that which causes them to begin to exist as things, under our hands and eyes" (Merleau-Ponty 1962, 162). Here, Carel points to Gallagher and Zahavi (2008) who consider the body "a constitutive or transcendental principle, precisely because it is involved in the very possibility of experience" (135). We dislike talk of the transcendental, for it invites conceptual ambiguities and carries a heavy load of historical baggage. Talk of the constitutive role of our bodies in experience, on the other hand, is more neutral and thus less problematic.

For Merleau-Ponty, it is our body's sensory experience that holds the key to subjectivity. While a denial of this intuitive idea may not be considered especially insightful today, philosophers in the mainstream have only recently started to take the idea seriously, sometimes explicitly citing Merleau-Ponty as their influence. As Godfrey-Smith (2016) argues:

Though the idea that our actions affect what we perceive seems routine and familiar, philosophers through many centuries did not 
treat it as especially important. In philosophy, this is the territory of unorthodoxies, of works beside, rather than within, the main development of ideas. That is true even in recent years. Instead, a huge amount of work has looked at a small piece of the total picture; it has looked at the link between what comes in through the senses and the thoughts or beliefs that result. Little was usually said about the link to action, and even less about the way action affects what you sense next.

- Peter Godfrey-Smith (2016, p. 80-81)

Carel (2011), likewise, highlights how influential Merleau-Ponty's views were at the time, stating that his idea of understanding human nature through our body and perception was a "radical one in the context of the history of philosophy, in which rationalism and an emphasis on a disembodied mind have been central" (p. 36). Indeed, his ideas are still considered radical, but may well hold the key to understanding not only human illness, but as we argue, also animal illness and suffering.

Perhaps something like this is already implicit in the work of many phenomenologists when they speak of "the kind of creature we are" (Carel 2011, p. 36), experiences being shaped by our bodies and brains, and the unity between minds and bodies. Carel (2011) seemingly makes this explicit, when she asserts that Merleau-Ponty provides us with a more "organic view of the human being as a human animal" that seeks to place the "body as the seat and sine qua non of human existence" (36-37). That we are "perceiving, feeling, and thinking animal[s]" (36) is indeed a more organic - i.e. biological - view than is usually found in traditional philosophy. Yet, we should stress here that this recognition of a continuity between humans and other animals is unfortunately not a core feature of phenomenology. Merleau-Ponty scholar Ted Toadvine (2014) notes that:

It is precisely this common animal sensibility that is repeatedly contested in the development of phenomenology after Husserl, in different ways and with different stakes, by Scheler, Heidegger, Sartre, and Levinas. Arguably, it is only Merleau-Ponty, among the major phenomenologists of the twentieth century, who endorses something like an animal stratum of the human and finds in it the basis for what he will eventually call a "strange kinship" (1995, 339/2003, 271).

- Ted Toadvine (2014) 


\subsection{Merleau-Ponty and Animal Phenomenology}

While it is Merleau-Ponty who among the major phenomenologists takes the most time to discuss animals, he only discusses them extensively in his first book The Structure of Behavior. ${ }^{4}$ Ted Toadvine (2007) hypothesizes that similar to Heidegger's (1962) Being and Time, Merleau-Ponty's early work might simply be intended as an illumination of the more 'private mode of existence': something we share with other animals, but that is ultimately only a small part of human experience. This is not Toadvine's preferred explanation, however, as it stands in conflict with Merleau-Ponty's final lecture on nature where he asserts that "there is no break between the planned animal, the animal that plans, and the animal without plan" (Merleau-Ponty 2003, 176):

Rather than starting from human perceptual consciousness and working backward, privatively, to disclose the essential structures of animal life, Merleau-Ponty starts from animal life and its Umwelt to demonstrate that Being is constitutively phenomenal.

- Ted Toadvine $(2007,18)$

This analysis of Merleau-Ponty is a highly interesting one, for it shows his admiration for Edmund Husserl who describes the constitution of Being in precisely this order (see Beyer 2018; Husserl 1913; 1980; 1989), and it suggests that he might have been one of the earliest philosophers to attempt to provide a naturalized account of phenomenology. ${ }^{5}$

There is thus an odd alliance between the more biologically-informed and oriented philosophies found in Godfrey-Smith (2016), Dennett (2017), and Ginsburg and Jablonka (2019), and embodied phenomenology in the tradition of Merleau-Ponty. Both share a common thread of attack against traditional 'rationalist' philosophy and instead seek to ground consciousness in nature, rather than human conscious experience. One might describe this as a bottom-up rather than top-down approach. Godfrey-Smith (2016) is thus right when he recognizes that the approach he and other naturalists follow is only now moving into the mainstream of philosophy, giving perhaps too little credit to its precursors in the phenomenological tradition.

\footnotetext{
${ }^{4}$ See Toadvine (2007) for an extended discussion on the Human-Animal relationship in Merleau-Ponty.

5 Indeed, Merleau-Ponty was directly influenced by the German psychologist Wolfgang Köhler, who studied chimpanzee cognition (see Toadvine 2019).
} 
As alluded to previously, the role of embodiment is taken seriously in much of the recent work in the cognitive sciences, and some have even attempted to naturalize phenomenology. ${ }^{6}$ It is within this tradition that Carel locates her work on the phenomenology of illness. Yet, she also claims that the "experience of illness cannot be captured within a naturalistic view" (Carel 2007, 95).

Here, it can be tricky to draw a distinction between those that try to provide a naturalized account of first-person experience (i.e. consciousness or sentience) and those who come from within the phenomenological tradition. We are not interested in drawing such a distinction here, yet remain faithfully in the camp that treats our first-person experience as something that can be explained and understood using the tools of science. We see the parts of phenomenology we draw on here as within science, rather than outside of it. Let us now turn to the phenomenology of illness, which can further illustrate this point.

\subsection{What is it like to be ill?}

Pathologies can be described entirely in objective-naturalist terms from a thirdperson point of view, but yet they are also experienced from a first-person perspective. Phenomenology is associated with someone's first-person experience. The phenomenology of illness is thus the 'what it is like'-ness or subjective experience of being in a pathological state. This is particularly problematic for animals as if we want to understand animal illness, how could we possibly gain access to the subjective experience of non-human animals?

Carel (2007) argues that the naturalist account of disease and pathology as mere dysfunction is not enough to account for the experience of illness, leading medical practitioners to discount the perspectives of patients. ${ }^{7}$ Here, MerleauPonty's embodied phenomenology plays a key role. Carel (2011) describes it as a "fleshly physical existence" (39), which is also reflected in the title of her later book llness: The Cry of Flesh (2018). Illness is a lived experience and has a distinct phenomenological character. With this we agree. While there is a link between being in a pathological state and experiencing pain and suffering, this need not be. Animals, just like humans, can be happy despite being in a pathological state. While it is hard to conduct scientific studies on these matters,

\footnotetext{
${ }^{6}$ See for instance the collected volume by Jan Petitot and Roy (1999).

${ }^{7} \mathrm{An}$ instance of this is the failure of researchers to take the perspectives of the entire autism spectrum seriously (see Chapman and Veit 2020).
} 
we should not discard the evidence coming from anecdotal reports of zookeepers, veterinarians, and animal researchers more generally. ${ }^{8}$

An example Carel (2011) draws from Merleau-Ponty is the phenomenon of phantom limbs. Phantom limbs are still considered a mysterious phenomenon in science (Kaur and Guan, 2018). How is it that we can have sensory experiences from a limb that has been amputated? Here, embodied phenomenology provides an answer: "[t]o have a phantom arm is to remain open to all the actions of which the arm alone is capable; it is to retain the practical field which one enjoyed before mutilation" (Merleau-Ponty, 1962, 81-82). Objectively the body part is gone, but the subject retains the subjective experience of having an arm - a sort of 'what is it like to have an arm'-ness remains. Carel (2011) expands on this example and argues that a "phantom limb is the expression, based on years of having a body image and a body schema with four limbs, of the body as it used to be. The habitual body is a relationship to an environment and to a set of abilities that are no longer available to the amputee" (40). This is further supported by the current classification of phantom limb pain as just one sub-part of the more general phantom complex (PC) phenomenon, which can include any bodily sensation apparently coming from an absent limb (Menchetti et al. 2017).

We have little doubt that there is much to gain from a phenomenological perspective on illness. It has helped us to better understand and take seriously the experiences of mental disorders such as autism (Chapman and Veit, 2020) and schizophrenia (Kendler, 2016). What we want to argue for here, however, is that we can extend these arguments to our fellow creatures: non-human animals. We will begin with some recent empirical work on phantom complex in canines.

\section{$4 \quad$ Measuring Animal Phenomenology}

One of the biggest concerns in defending an account of animal phenomenology is how it is that we might gain access to information about the phenomenal states of animals. After all, these states are necessarily private, and unlike humans, animals cannot tell us about their experience. However, there are a number of emerging methods that can tell us about animal phenomenology, and their experiences of health and welfare.

As we discussed above, phantom limbs are a crucial support point in the application of phenomenology to human illness, and we will now turn to whether

\footnotetext{
${ }^{8}$ See Browning $(2017,2018 a, b)$.
} 
phenomenology can illuminate PC in non-human animals. Recent work by Menchetti et al. (2017) on PC in dogs is the first of its kind. While there has been prior work on the ability of small animals with amputated legs to adapt and the impact on their welfare (Kirpensteijn et al., 1999; Dickerson et al., 2015; Raske et al,. 2015), no work has focused on the question of whether they are able to experience phantom limbs. Menchetti et al. (2017) created a survey for dog owners in order to "identify signs and behaviors suggestive of neuropathic pain, evaluate risk factors associated with PC occurrence, and determine the owners' perceptions of the quality of life (QoL) of their 3-legged pets" (25). In their design, they oriented themselves on the work in humans, through use of similar questionnaires and behavioural assessments. Their results indicated some striking similarities to self-reports made by humans after amputations. Some canines, for instance, underwent personality changes after the amputation of their limbs, showing increased aggression and anxiety where it is not clear whether this must be related to pain. ${ }^{9}$ These novel results are interesting. As Carel (2011) notes, "mood as an existential category is a significant dimension of illness" (44). There is no reason to think that at least some higher vertebrates do not have perhaps a proto-form of such existential experiences. ${ }^{10}$

A phenomenology in the style of Carel might thus very well hold the key to understanding such behavioural and emotional changes in animals. Could it be possible that a dog experiences anger, fear, and frustration after no longer being able to experience his life the way his body previously enabled him to? Our answer suggests a resounding yes. We see no reason to think that this bodily experience would be different for humans than for other mammals. ${ }^{11}$

A possible experiment for this could be to test whether animals with amputations change their "view of the world" - here drawing on the literature on optimism and pessimism in animals. As we will discuss below, it has been shown that animals that have experienced primarily negative states (environments with low reward opportunities) are subject to seeing ambiguous signals as threats, and thus treat the epistemic likelihood of events more 'pessimistically' (and the reverse true for positive states and optimism) (Mendl et al., 2010). An animal's mood state "may thus act as a heuristic device influencing cognitive processes and facilitating appropriate decision-making behaviour" (Mendl et al., 2010, 2900)

\footnotetext{
${ }^{9}$ Menchetti et al. (2017) note that similar results were found in Kirpensteijn et al. (1999).

${ }^{10}$ For moral concerns, however, it is not relevant whether the animals in question have high cognitive capacities and understand their disease in any sophisticated way - what matters is whether they suffer (Dawkins 2001; Browning 2019c).

${ }^{11}$ The jury is still out on other vertebrates, and invertebrates.
} 
and further serve as an indicator for an animal's assessment of its own sense of 'being in the world'.

Menchetti et al. (2017) conclude their paper with a recognition that the "ability to recognize behavioral signs that may indicate the presence of unpleasant sensations related to neuropathic pain would be of great interest, to prevent and treat it" (27). Neuropathic pain (i.e. unprompted pain without any apparent cause) is notoriously difficult to understand in humans, but even more so in non-human animals, since they cannot verbalize their discomfort in the same way humans do (Mathews 2008). Some animals - for instance those with a high tolerance for pain, or prey animals that evolved to hide their weakness from predators - may show no external signs of pain, despite actually suffering.

Now one might wonder what the phenomenological role or component in such studies is. We think it is substantial. ${ }^{12}$ As Carel (2011) notes, embodied phenomenology is importantly different:

Phenomenology, in its embodied understanding of human being, differs from other first-person approaches such as certain narrative approaches and qualitative interviews. This is particularly important when we come to think of actual research methods [...] that go beyond verbal accounts. They may use 'walking with' exercises, videotaping (thus including nonverbal information about bodily movement and gestures), and reports relating sensual and perceptual experiences (e.g., looking at changes to sense of taste).

Havi Carel $(2011,41)$

Such qualitative measures are empirical and do not necessitate verbal responses. They are nevertheless phenomenological and could be applied to animals. Indeed, we argue that there already exist such qualitative phenomenological tools for the assessment of an animal's experience.

Perhaps the most promising of these is Qualitative Behavioural Assessment (QBA) (Wemelsfelder et al., 2001). QBA is a profiling method through which trained observers are able to take a whole-body approach to assess the overall experience of an animal. Observers watch an animal as it interacts with its environment, incorporating its behaviour and body language into a judgement about the animal.

12 There will always persist a danger in trying to over-rationalize the behavior of other life-forms (Veit et al. 2020; Veit 2019a) and we suggest tackling this problem with pluralism, rather than a-priori limitations. We expand on this point in the conclusion. 
These assessments can be transformed into quantitative scoring methods with quite high reliability for applications in animal husbandry and welfare (Browning 2020). This holistic approach uses the observer as a "research instrument" (Beausoleil and Mellor 2011, 457), who unconsciously integrates incoming information from the behaviour and body language of the animal to form an overall picture about its experience. The individual behaviours themselves are not the focus, instead it is the style of behaviour, the way in which the animal moves through and interacts with its environment. It is a whole-body measure, reflecting the overall state of the animal; an integrated output of the various experiences and the way in which they impact the animal as a whole. This method has shown high reliability, with different observers giving similar assessments, and strong correlation with other established indicators of animal health and welfare (Fleming et al., 2016). It seems that, as human animals, we are responding to our own intuitive understanding of phenomenological experiencing and its impact on being and action. This method relies heavily on the relationship between experiencing and acting, between mind and body, that underpins the phenomenological tradition. ${ }^{13}$

Another successful method for understanding animal experience as it pertains to welfare is cognitive bias testing. Here, we can usefully refer back to our discussion of an animal's mood above. The processes of cognition can alter in response to experience in measurable ways and cognitive bias testing takes advantage of this fact (Mendl et al., 2010). In these tests, animals are trained such that they will expect a reward when perceiving one stimulus, such as the arrival of some food when a light appears in the left corner of the room, and a punishment under another, such as a puff of air in the face when a light appears in the right corner. When the animals are presented with an ambiguous signal - a light somewhere in the middle of the room - the way they perceive and react to this will depend on their previous experience. Animals that have had positive experiences, and thus high welfare, will behave optimistically, as though they are about to receive a reward. Animals that have had prior negative experiences, with corresponding low welfare, will behave pessimistically and anticipate the punishment. Thus, the degree of optimistic or pessimistic bias exhibited will tell us about the overall mood or state of subjective welfare of the animal, regarding the total of its previous life experiences.

13 The 'subjective' welfare concept grounding these measures stands in contrast with the historically behaviorist welfare concept that sought to ground animal welfare in their teleological 'natural behaviour' and is, for instance, now being applied in zoos (Browning 2019a; Browning and Maple 2019). 
Since all experiences are embodied experiences, there is no reason to think that a negative change to the body wouldn't lead to negative mental states. Negative bodily changes, such as the loss of a limb, or presence of disease, will create negative mental states such as pain, nausea, fear or anxiety. The presence of these mental states will have an impact on overall mood. Any experience that has an impact on mental states will then be detectable with this sort of testing, to find whether an animal has experienced a change in its embodied phenomenology.

As the large literature on self-medication behaviour in animals (see Neco et al. 2019) suggests, animals may be acutely aware that something has 'gone wrong' with their bodies. For example, rodents in pain will voluntarily self-administer analgesic medications when given the opportunity (Martin and Ewan 2008). As another example, wild primates will treat internal parasites by eating whole leaves and external parasites by rubbing their skin with acidic plant parts, and even in some cases with millipedes (Neco et al. 2019). The phenomenological experiences of animals, the positive and negative experiences that constitute welfare, do not just impact the body, but also the workings of the mind itself, in ways the animals respond to.

\section{Implications for our Treatment of Animals}

The phenomenology (i.e. subjective experience) of different animals might be radically different from one another, and thus have an impact on how we should treat these animals. One of us (Browning 2019b), has previously argued that the different phenomenological experiences of octopuses should make us reluctant to create ethical standards, legislation, and regulations, for the protection of cephalopods without taking their different experiences into account.

Lights which appear gentle to the human eye may not be so within the octopus perceptual range, so light polarisation should also be measured and taken into account. Chemicals within the tank can affect health but may also be pleasant or aversive in ways we may not usually consider. Chemosensory enrichment opportunities could open up new avenues of exploration. Vibrations through the water can have a large impact on octopus health and welfare (e.g., André et al. 2011), with "noise and vibration control" forming a core part of the guidelines for octopus husbandry $[\ldots]$

- Heather Browning (2019b, 34) 
These results suggest that a phenomenological approach to animal health and ethics is a useful one - gaining attention both among scientists and the public. ${ }^{14}$ Low-frequency sounds have been shown to induce acoustic trauma in octopuses and are thus of relevance to cephalopod pathology (André et al. 2011; AZA Aquatic Invertebrate Taxon Advisory Group (AITAG) 2014; Fiorito et al. 2014). Indeed, the above paper emphasizes this conclusion by making an explicitly phenomenological point: "it is only by trying to see the world from their point of view that we will be able to find out what is good for them and hence ensure their welfare" (Browning 2019b, 2). A further issue in which the phenomenological perspective will be relevant, is the debate surrounding euthanasia (Browning 2018b) and slaughter of animals (Browning \& Veit, 2020). If an animal can be happy despite being in a pathological state, this should give us pause in accepting euthanasia of sick animals as unproblematic. 'Taking the viewpoint' of an animal is no longer seen as merely metaphorical, but it is a genuine scientific method towards understanding our fellow creatures, with real and important implications for how we should treat them if we want to ensure their wellbeing.

\section{Conclusion}

As one of us has argued in previous publications (Veit 2020a,d), science thrives by creating a vast range of different lenses, models, and tools offering different perspectives on the phenomena under investigation. Early phenomenologists had some anti-scientific (or at least anti-reductionist) attitudes, thinking that philosophers and scientists left out an important domain of life - i.e. our subjective and embodied experience. ${ }^{15}$ Now, both scientists and philosophers within the mainstream have begun to take this strand of thought more seriously. This can only be recommended. There is no simple either-or in this domain, even if philosophers seem to trip easily into seeing the matter in black and white.

A phenomenological approach to animals is thus promising for revealing relevant facts not only about what it is like to be a bat, an octopus, or a human in a pathological state, but also what we should do in relation to their welfare - an issue that is of importance in bioethics. 'Perspectival pluralism' in the sense of Giere (2006), Massimi (2012), and Veit (2020a,d, 2019b) will help us to better understand our non-human neighbours by embracing a plurality of alternative perspectives; phenomenology being one of them. We thus hope to have dispelled

\footnotetext{
14 See Veit (2020b,c); Veit and Harnad (2020); Veit and Rowan (2020).

15 See also Rosenberg (2011) and Veit (2018a).
} 
at least some of the initial reservations among those who regarded phenomenology as a practice solely applicable to humans. Animal experience is real and needs to be taken seriously - both for ethical and scientific purposes. While we cannot literally hear their voices, there are good phenomenological, yet nevertheless qualitative empirical methods, that can help us to, at least indirectly, make them heard. 


\section{References}

André, M., M. Solé, M. Lenoir, M. Durfort, C. Quero, A. Mas, A. Lombarte, M. Van der Schaar, M. L'opez-Bejar, M. Morell, et al. (2011). Lowfrequency sounds induce acoustic trauma in cephalopods. Frontiers in Ecology and the Environment 9(9), 489-493.

AZA Aquatic Invertebrate Taxon Advisory Group (AITAG) (2014). Giant Pacific octopus (Enteroctopus dofleini) care manual. Silver Spring, MD: Association of Zoos and Aquariums.

Beausoleil, N. J. and D. J. Mellor (2011). Complementary roles for Systematic Analytical Evaluation and qualitative Whole Animal Profiling in welfare assessment for Three Rs applications. Proceedings of the 8th World Congress on Alternatives and Animal Use in the Life Sciences, Montreal, Canada, 2125.

Beyer, C. (2018). Edmund Husserl. The Stanford Encyclopedia of Philosophy, Edward N. Zalta (ed.), URL = $<$ https://plato.stanford.edu/archives/sum2018/entries/husserl/>.

Browning, H. (2017). Anecdotes can be evidence too. Animal Sentience: An Interdisciplinary Journal on Animal Feeling 2(16), 13.

Browning, H. (2018a). Book Review of Jenny Gray: Zoo Ethics: The Challenges of Compassionate Conservation. Quarterly Review of Biology 92(2), 149.

Browning, H. (2018b). No Room at the Zoo: Management Euthanasia and Animal Welfare. Journal of Agricultural and Environmental Ethics 31(4), 483-498.

Browning, H. (2019a). The natural behavior debate: Two conceptions of animal welfare. Journal of Applied Animal Welfare Science, 1-13.

Browning, H. (2019b). What is good for an octopus? Animal Sentience 4(26), 7. 
Browning, H. (2019c). What should we do about sheep? The role of intelligence in welfare considerations. Animal Sentience 4(25), 23.

Browning, H. and T. L. Maple (2019). Developing a Metric of Usable Space for Zoo Exhibits. Frontiers in Psychology 10, 791.

Browning, H. and W. Veit (2020). Is Humane Slaughter Possible? Animals 2020, 10, 799. https://doi.org/10.3390/ani10050799

Browning, H. (2020). Assessing Measures of Animal Welfare. Preprint. http://philsci-archive.pitt.edu/17144/

Carel, H. (2007). Can I be ill and happy? Philosophia 35(2), 95-110.

Carel, H. (2011). Phenomenology and its application in medicine.

Theoretical Medicine and Bioethics 32(1), 33-46.

Carel, H. (2018). Illness: The cry of the flesh. Routledge.

Chapman, R. and W. Veit (2020). Representing the Autism Spectrum. The American Journal of Bioethics 20(4), 46-48. https://doi.org/10.1080/15265161.2020.1730495

Dawkins, M. S. (2001). Who needs consciousness? Animal Welfare 10, S1929.

Dennett, D. C. (2017). From bacteria to Bach and back: The evolution of minds. WW Norton \& Company.

Dickerson, V. M., K. D. Coleman, M. Ogawa, C. F. Saba, K. K. Cornell, M. G. Radlinsky, and C. W. Schmiedt (2015). Outcomes of dogs undergoing limb amputation, owner satisfaction with limb amputation procedures, and owner perceptions regarding postsurgical adaptation: 64 cases (2005-2012). Journal of the American Veterinary Medical Association 247(7), 786-792.

Fiorito, G., A. Affuso, D. B. Anderson, J. Basil, L. Bonnaud, G. Botta, A. Cole, L. D’Angelo, P. De Girolamo, N. Dennison, et al. (2014). Cephalopods in 
neuroscience: regulations, research and the 3Rs. Invertebrate Neuroscience 14(1), 13-36.

Fleming, P. A., T. Clarke, S. L. Wickham, C. A. Stockman, A. L. Barnes, T. Collins, and D. W. Miller (2016, September). The contribution of qualitative behavioural assessment to appraisal of livestock welfare. Animal Production Science 56(10), 1569-1578.

Gallagher, S. and D. Zahavi (2008). The phenomenological mind. Routledge. Giere, R. N. (2006). Perspectival pluralism. In S. H. Kellert, H. E. Longino, and C. K. Waters (Eds.), Scientific Pluralism, Chapter 2, pp. 26-41. Minneapolis: University of Minnesota Press.

Ginsburg, S. and E. Jablonka (2019). The Evolution of the Sensitive Soul: Learning and the Origins of Consciousness. Cambridge: MIT Press.

Godfrey-Smith, P. (2016). Other minds: The octopus, the sea, and the deep origins of consciousness. Farrar, Straus and Giroux.

Heidegger, M. (1962). Being and Time. New York: HarperCollins. Translated from the German Original (1927) by John Macquarrie and Edward Robinson.

Husserl, E. (1913). Ideas Pertaining to a Pure Phenomenology and to a Phenomenological Philosophy-First Book: General Introduction to a Pure Phenomenology, trans. F. Kersten. The Hague: Nijhoff 1982 (= Ideas).

Husserl, E. (1980). Ideas Pertaining to a Pure Phenomenology and to a Phenomenological Philosophy-Third Book: Phenomenology and the Foundations of the Sciences, trans. T. E. Klein and W. E. Pohl, Dordrecht: Kluwer.

Husserl, E. (1989). Ideas Pertaining to a Pure Phenomenology and to a Phenomenological Philosophy—Second Book: Studies in the Phenomenology of Constitution, trans. R. Rojcewicz and A. Schuwer, Dordrecht: Kluwer.

Jan Petitot, Franciso J. Varela, B. P. and J.-M. Roy (1999). Naturalizing Phenomenology: Issues in Contemporary Phenomenology and Cognitive Science. Stanford University Press. 
Kaur, A. and Y. Guan (2018). Phantom limb pain: A literature review. Chinese Journal of Traumatology 21(6), 366-368.

Kendler, K. S. (2016). Phenomenology of schizophrenia and the representativeness of modern diagnostic criteria. JAMA psychiatry 73(10), $1082-1092$.

Kirpensteijn, J., R. Van den Bos, and N. Endenburg (1999). Adaptation of dogs to the amputation of a limb and their owners' satisfaction with the procedure. Veterinary Record 144(5), 115-118.

Marder, M. (2012). Plant intentionality and the phenomenological framework of plant intelligence. Plant signaling \& behavior, 7(11), 1365-1372.

Martin, T. J. and E. Ewan (2008). Chronic pain alters drug selfadministration: Implications for addiction and pain mechanisms. Experimental and Clinical Psychopharmacology 16(5), 357-366.

Massimi, M. (2012).

SCIENTIFIC PERSPECTIVISM AND ITS FOES. Philosophica 84, 25-52.

Mathews, K. A. (2008). Neuropathic pain in dogs and cats: if only they could tell us if they hurt. Veterinary Clinics of North America: Small Animal Practice $38(6), 1365-1414$.

Menchetti, M., G. Gandini, A. Gallucci, G. Della Rocca, L. Matiasek, K. Matiasek, F. Gentilini, and M. Rosati (2017). Approaching phantom complex after limb amputation in the canine species. Journal of Veterinary Behavior 22, 24-28.

Mendl, M., O. H. P. Burman, and E. S. Paul (2010, October). An integrative and functional framework for the study of animal emotion and mood. Proceedings of the Royal Society B: Biological Sciences 277(1696), 28952904.

Merleau-Ponty, M. (1962). Phenomenology of perception. New York: Routledge. 
Merleau-Ponty, M. (1983). The Structure of Behavior. Pittsburgh: Duquesne University Press. Translation from French by Alden Fisher.

Merleau-Ponty, M. (2003). Nature: Course notes from the Coll'ege de France. Northwestern University Press. Translation by Robert Vallier.

Nagel, T. (1974). What is it like to be a bat? The philosophical review 83(4), 435-450.

Neco, L. C., E. S. Abelson, A. Brown, B. Natterson-Horowitz, and D. T. Blumstein (2019, August). The evolution of self-medication behaviour in mammals. Biological Journal of the Linnean Society.

Raske, M., J. McClaran, and A. Mariano (2015). Short-term wound complications and predictive variables for complication after limb amputation in dogs and cats. Journal of Small Animal Practice 56(4), 247-252.

Rosenberg, A. (2011). The atheist's guide to reality: Enjoying life without illusions. New York, NY: WW Norton \& Company.

Svenaeus, F. (2000a). The body uncanny-Further steps towards a phenomenology of illness. Medicine, Health Care and Philosophy 3(2), 125137.

Svenaeus, F. (2000b). Das unheimliche-towards a phenomenology of illness. Medicine, Health Care and Philosophy 3(1), 3-16.

Svenaeus, F. (2001). The hermeneutics of medicine and the phenomenology of health: Steps towards a philosophy of medical practice. Linkoping: Springer.

Toadvine, T. (2007). "Strange Kinship": Merleau-Ponty on the HumanAnimal Relation. In Phenomenology of Life from the Animal Soul to the Human Mind, pp. 17-32. Springer.

Toadvine, T. (2014). The Time of Animal Voices. Konturen 6(0), 22-40. 
Toadvine, T. (2019). Maurice Merleau-Ponty. In E. N. Zalta (Ed.), The Stanford Encyclopedia of Philosophy.

Toombs, S. K. (1987). The meaning of illness: a phenomenological approach to the patient-physician relationship. The Journal of medicine and philosophy 12(3), 219-240.

Toombs, S. K. (1988). Illness and the paradigm of lived body. Theoretical medicine 9(2), 201-226.

Toombs, S. K. (2001). The role of empathy in clinical practice. Journal of Consciousness Studies 8(5-6), 247-258.

Veit, W. (2018a). Existential Nihilism: The Only Really Serious Philosophical Problem. Journal of Camus Studies, 211-232.

Veit, W. (2018b). Procreative Beneficence and Genetic Enhancement. Kriterion - Journal of Philosophy 32(1), 75-92.

Veit, W. (2018c). Enhancement technologies and inequality. In C. Saborido, S. Oms, and J. G. de Prado (Eds.), Proceedings of the IX Conference ofthe Spanish Society of Logic, Methodology and Philosophy of Science, pp. 471476.

Veit, W. (2018d). Cognitive enhancement and the threat of inequality. Journal of Cognitive Enhancement 2(4), 404-410.

Veit, W. (2019a). Evolution of multicellularity: cheating done right. Biology \& Philosophy 34(3), 34.

Veit, W. Modeling Morality (2019b). In L. Magnani, A. Nepomuceno, F. Salguero, C. Barés and M. Fontane (eds), Model-Based Reasoning in Science and Technology, Springer. https://doi.org/10.1007/978-3-030-32722-4_6

Veit, W. (2020a). Model Pluralism. Philosophy of the Social Sciences 50(2), 91-114. 
Veit, W. (2020b). The Octopus and the Unity of Consciousness. Psychology Today. $\quad$ https://www.psychologytoday.com/au/blog/science-andphilosophy/202003/ the-octopus-and-the-unity-consciousness.

Veit, W. (2020c). What is good for an Octopus. Psychology Today. https: //www.psychologytoday.com/au/blog/science-and-philosophy/202003/whatis-good-octopus.

Veit, W. (2020d). Model Anarchism. Preprint. DOI: 10.13140/RG.2.2.36694.47683

Veit, W., J. Dewhurst, K. Dolega, M. Jones, S. Stanley, K. Frankish, and D. C. Dennett (2020). The Rationale of Rationalization.Behavioral andBrain Sciences 43, e53.

Veit, W. and S. Harnad (2020). 4 Years of Animal Sentience. Psychology Today. $\quad$ https://www.psychologytoday.com/blog/science-andphilosophy/202003/4-years-animal-sentience.

Veit, W. and A.N. Rowan (2020). The Rising Concern for Animal Welfare. Psychology Today. https://www.psychologytoday.com/au/blog/science-andphilosophy/202003/the-rising-concern-animal-welfare.

Wemelsfelder, F., T. E. Hunter, M. Mendl, and A. B. Lawrence (2001, August). Assessing the 'whole animal': a free choice profiling approach. Animal Behaviour 62(2), 209-220.

Wiggins, O. P. and J. Z. Sadler (2005). A Window Into Richard M. Zaner's Clinical Ethics. Theoretical medicine and bioethics 26(1), 1-6.

Wiggins, O. P. and M. A. Schwartz (2005). Richard Zaner's phenomenology of the clinical encounter. Theoretical medicine and bioethics 26(1), 73-87.

Zaner, R. M. (1981). Context of self: A Phenomenological Inquiry Using Medicine as a Clue. Ohio University Press. 
Zaner, R. M. (2005). A work in progress. Theoretical medicine and bioethics 26(1), 89-104. 
animal, 1, 2, 3, 4, 6, 7, 9, 10, 11, 12, $13,14,15,17,20,23$

Carel, Havi, 1, 2, 3, 4, 5, 6, 8, 9, 10, $11,12,18$

cognitive bias, 11,13

consciousness, $1,3,7,8,18,19,23$

embodiment, 2, 5, 8, 9, 12, 13, 14, 15

health, 1, 9, 15, 21

illness, 2, 4, 5, 6, 8, 9, 10, 21, 22
Merleau-Ponty, 2, 4, 5, 6, 7, 8, 9, 21, 22

octopus, 14, 15, 17, 19, 23

pathology. See health

phantom limb, 2, 10

phantom complex, 10, 11, 20

Qualitative Behavioural Assessment, 2,12

self-medication, 2, 14, 21

suffering, 1, 2, 4, 5, 6, 9, 12 